\title{
Analysis of the final comments provided by a knowledgeable other in lesson study
}

\author{
Tatsuhiko Seino $^{1}$ (D) $\cdot$ Colin Foster $^{2}$ (D)
}

Published online: 23 June 2020

(c) The Author(s) 2020

\begin{abstract}
Lesson study has been implemented in schools around the world as a method of professional development for teachers. Lesson study consists of five steps, among which the "Research Lesson" and "Post-lesson Discussion" are central. During the Post-lesson Discussion, after the teacher has commented on the lesson, all of the observers discuss the lesson, and the "knowledgeable other" (koshi), a specially invited expert, provides final comments. The quality of these final comments is critical to the learning of the lessonstudy participants, and, consequently, the koshi plays an extremely important role. However, few studies have examined the nature and structure of the final comments that koshis provide. This study analyzed the final comments made in three elementary-school research lessons in Japan by a highly distinguished university mathematics educator with considerable teaching experience and an outstanding reputation as a koshi. We found that his final comments clustered into seven categories, which we named: (1) considering the didactical value of mathematical content; (2) use of representations; (3) fostering positive attitudes to learning; (4) incorporating students' ideas into whole-class discussions; (5) giving attention to what students write down; (6) giving attention to the content of the board-work; and (7) teacher growth through reflection. These categories provide insight into the nature of final comments that are regarded as being particularly useful and may form the basis for less-experienced koshis to structure their final comments in lesson study.
\end{abstract}

Keywords Final comments · Knowledgeable other · Lesson study · Post lesson Discussion · Structured problem solving

Electronic supplementary material The online version of this article (https://doi.org/10.1007/s1085 7-020-09468-y) contains supplementary material, which is available to authorized users.

Tatsuhiko Seino

tseino@u-gakugei.ac.jp

Colin Foster

c.foster@lboro.ac.uk

1 Faculty of Education, Tokyo Gakugei University, 4-1-1 Nukuikita-machi, Koganei-shi, Tokyo 184-8501, Japan

2 Mathematics Education Centre, Schofield Building, Loughborough University, Loughborough LE11 3TU, UK 


\section{Introduction}

Lesson study is a powerful form of professional development, which enables Japanese teachers to improve their lessons and enhance their teaching competence (Fernandez and Yoshida 2012). In recent years, many other countries have sought to adopt and adapt aspects of lesson study for use in their own schools, especially in mathematics (Baldry and Foster 2019; Groves et al. 2016; Lewis 2002; Stigler and Hiebert 1999; Takahashi and McDougal 2016; Takahashi and Yoshida 2004; Yoshida 1999). However, for Japanese teachers, lesson study is so familiar that it is "like air" (Fujii 2014, p. 80), meaning that essential aspects of the process may be taken for granted and not critically interrogated. This means that it can be hard for those new to lesson study-whether teachers in other countries, or less-experienced teachers in Japan-to learn about how to enact the process in the most effective ways possible. To achieve this, it is necessary to examine aspects of successful lesson study in Japan in considerable detail, so that practices that contribute to the effectiveness of the process can be captured, codified and analyzed.

Lesson study is commonly conceived of in five steps (Fujii 2016): Goal Setting, Lesson Planning, Research Lesson, Post-lesson Discussion, and Reflection. When a new school academic year begins in Japan, Japanese teachers set research themes for the year under the leadership of a 'chief researcher,' a teacher at the school charged with that particular role. Various factors are considered, such as the latest developments in technology, any changes to the course of study, the research history of the school, and the current learning of the children in the school, and a suitable research theme is decided on. One example could be: "To help children to think for themselves and learn actively together: improvement of mathematical thinking, decision making, and expressing." Following this goal setting, the next step involves designing a lesson that will address the research theme. A lesson plan is created based on deep research into the teaching materials (kyouzai kenkyuu). At the three schools studied by Fujii (2016), meetings were held for about 4-6 weeks to develop a lesson plan for one lesson. Following this, the research lesson is taught by one of the teachers in the planning group, and then, in the Post-lesson Discussion, the lesson is considered in detail, drawing on notes made by the observers during the lesson. The purpose of the Postlesson Discussion is to very carefully analyze the learning of the students in the research lesson, organize the knowledge obtained through the research lesson, clarify how the lesson could be improved, and create a school bulletin as a summary of the school's research for that year. The terms Lesson study and research lesson are sometimes viewed as synonymous, but they are distinct, as a research lesson is one component of lesson study (Fujii 2016).

The Post-lesson Discussion is a critical opportunity for all of the teachers and observers to reflect deeply on the lesson and consider how to improve their teaching. They can enhance their understanding of various teaching methods, become more expert at observing students' thinking, and learn how to examine teaching materials in greater depth. Thus, the Post-lesson Discussion plays a crucial role in the entire lesson-study process. However, it is not easy to make such a discussion effective for everyone. For a successful Postlesson Discussion, it is necessary to interpret and discuss students' thinking, difficulties, and transformation of thinking in the lesson, based on detailed information about what the students said and did. This requires detailed lesson notes from the observers. Moreover, during the Post-lesson Discussion, it is important to compare and contrast findings across the most recent research lessons, in order to develop principles for teaching (Wada 1953). 
The most important factor in ensuring a productive Post-lesson Discussion is the role of the "knowledgeable other" (koshi), who provides essential expertise to the process by making 'final comments' on the lesson, following a general group discussion. These final comments seek to draw out the most important learning points for the teachers and observers (Takahashi 2014; Takahashi and Yoshida 2004; Watanabe 2002; Watanabe and WangIverson 2005). Previous studies have clarified the role played by the koshi in lesson study, and the skills necessary for them to act in this role (Fernandez et al. 2001; Takahashi 2014; Takahashi and Yoshida 2004; Watanabe and Wang-Iverson 2005). However, we do not know the nature and structure of the final comments that expert koshis typically provide, or of those that are considered to be particularly useful.

In countries where lesson study is not yet firmly embedded in school culture, the importance of the role of the koshi may well be acknowledged, but those taking on this role may lack confidence in providing final comments in research lessons and may wonder what kinds of comments may be most helpful for the participants (e.g., Baldry and Foster 2019). Even in Japan, a new koshi will not yet have gained the experience that makes this process feel natural, and the quality of final comments is likely to be improved by giving attention to the final comments made by more experienced koshis.

The purpose of this study is to analyze the final comments made during the Post-Lesson Discussions of three elementary-school research lessons in Japan by a highly renowned koshi with an outstanding reputation as a koshi in Japan. By examining the nature of the final comments made in these lessons, we seek to answer the question: What kinds of topics are discussed by a highly-regarded knowledgeable other during the Post-lesson Discussions of mathematics research lessons? By answering this question, we intend to learn about what may constitute effective final comments in lesson study.

\section{The knowledge of a koshi}

In Japan, the role of the koshi is typically performed by a highly experienced former school teacher of mathematics who has subsequently moved to a position in a university. A koshi may also be a teacher from a school affiliated with a national university, a district/prefecture supervisor or a Principal from another school (Watanabe and Wang-Iverson 2005). Some schools invite the same koshi to give final comments for all of the research lessons taking place during 1 year, while other schools ask different koshis to give final comments each time.

We would expect that the knowledge of a koshi could be conceptualized as a developed version of the 'pedagogical content knowledge' (Shulman 1986) needed for mathematics teaching, which has been codified in constructs such as 'mathematical knowledge for teaching' (Ball et al. 2005) and the 'knowledge quartet' (Rowland 2008). As an expert teacher, a koshi might be expected to have a particularly high level of this kind of didactical mathematical knowledge (Andrews 2007). This includes common mathematical content knowledge, that is drawn on by many users of mathematics, as well as specialized content knowledge, which is particularly relevant for those teaching mathematics. Expert didactical knowledge particularly includes horizon content knowledge, which attends to the connections between different mathematical content areas, knowledge of the relationship between content and the students, knowledge of content and teaching methods, and knowledge of content and the curriculum (Ball et al. 2005), which in Japan includes knowledge of the 
approved textbooks and their effective use. However, we expect that there may be other kinds of knowledge needed to be an effective koshi, and these may relate to the different roles that a koshi needs to perform during Post-lesson Discussions.

Fernandez et al. (2001) regarded the role of the koshi in lesson study as: (1) providing a different perspective when studying the work of the group; (2) providing information about mathematics content, new ideas, or reforms, and (3) sharing the work of other lesson-study groups. In addition to the above roles, Watanabe and Wang-Iverson (2005) added "facilitation of discussions." These overlap with the three roles of the koshi that Takahashi (2014) derived, based on observations of final comments in Post-lesson Discussions, surveys of koshis, and interviews with three respected koshis. Takahashi's (2014) list consists of: (1) bringing new knowledge from research and the curriculum; (2) showing the connection between theory and practice; and (3) helping others to learn how to reflect on teaching and learning. Outside of Japan, where the lesson-study process itself is novel, a koshi might also need to be able to explain and support the establishment of this process in a school, among teachers who have never conducted lesson study before (Baldry and Foster 2019).

These criteria require a koshi to be able to provide access to a deeper understanding of the mathematical content, the curriculum, and the didactical ideas that have informed the way in which the textbooks have been designed (e.g., see Seino and Foster 2019), all of which reside within multiple aspects of mathematical knowledge for teaching (Ball et al. 2005). The koshi will seek to do this using concrete examples observed in the research lesson and to make links to the school's research theme, as well as suggesting in which directions the school's research might go next. Takahashi (2014) suggested that a koshi should have the ability to collect, evaluate, and use data in lessons, as well as broad knowledge regarding the goals of mathematics, the structure of the subject, students' development of mathematics, characteristics of student thinking, and expectations of the curriculum.

Beyond mathematical knowledge for teaching, Takahashi and Yoshida (2004) pointed out that the koshi should have: (1) the ability to read the audience and provide appropriate comments that help participants learn or want to learn; (2) the ability to point out something that no one in the audience has noticed, but that is important to learning about the topic; and (3) an attitude that he or she is also a learner through the lesson study and an appreciation of the teachers' efforts.

The demands on a koshi are clearly considerable, and the high expectations associated with a high-profile visit of a renowned koshi speaking at a well-attended research lesson add to the pressure. As the importance of the koshi in lesson study has increasingly been recognized, what koshis do and the role they play in lesson study have been clarified. In Japan, lesson study has a long history, and, since there are many koshis, one might suppose that much is known about how to learn to become a koshi and how to develop in the role. However, this is not the case. Consequently, in this study we analyzed the final comments made across three research lessons by a highly regarded koshi in order to uncover the themes stressed and developed. In this way, we hope to go beyond a statement of desirable roles and responsibilities to learn in more depth about how a koshi can be most effective in making final comments in Post-lesson Discussions. 


\section{Method}

\section{Selection of the koshi}

The purpose of this study was to analyze and organize the final comments made by a highly experienced koshi during the Post-lesson Discussions that took place during three elementary-school research lessons. Takahashi (2014) and Groves and Doig (2016) analyzed final comments made by many koshis. However, in this study, we instead focus on a single, highly experienced koshi. The reason for doing this is that in previous research the content of the final comments made differed greatly from one koshi to another, due to differences in perspectives on teaching, teaching materials, and students. In this study, we seek to minimize this variation by studying a single, highly experienced and renowned koshi, so that the main source of variation is the nature of the research lesson and the comments of the participants contributing to the Post-Lesson Discussion. We intend that by focusing on one highly expert koshi we will gain greater insight into the structure and choices made in arriving at the final comments.

The koshi in this study, Professor Takashi Nakamura, worked for 19 years in the faculty of education at the University of Yamanashi, after first working for 21 years at the university's attached elementary school. During his time as an elementary school teacher, Nakamura wrote several papers and books on mathematics education, using data from his own mathematics lessons. He also contributed as an author to government-approved elementary mathematics textbooks. During his time as a university academic, he conducted research on the meaning of multiplication of decimal numbers, proportion, use of student reflective journals, and lesson study. He also contributed to writing a course of study on elementary mathematics. As a koshi, he provided final comments at school-based, district-based, and national-level Lesson Studies for a total of about 60 research lessons per year (Nakamura 2011a). Sometimes, he also conducted demonstration lessons as an actual teacher.

Takahashi (2014) pointed out the bridge between theory and practice as a role of the knowledgeable other. Having studied the theory of mathematics education as well as having abundant practical experience as a classroom teacher, Nakamura was perceived as exceptional in his ability to bridge between theory and practice (Takahashi 2014). At the start of this study, our intention was to work collaboratively with Nakamura, by analyzing his final comments, as well as seeking to uncover the intentions behind his final comments by conducting interviews with him. To our great sadness, however, this was not possible, because Nakamura passed away in 2016, before the study was completed. Instead, therefore, we have chosen to interpret and suggest possible intentions behind Nakamura's final comments by referring to our detailed reading of his many papers and books, and we include selected extracts from these in the analysis below.

Because of Nakamura's deep involvement in and commitment to this research before his death, we are completely confident of his consent in us publishing this research posthumously, and without anonymity. Indeed, by studying his thoughts and expert final comments, we seek to ensure that they will not be buried.

\section{Data sources and analysis}

Lesson study in Japan is sometimes categorized into school-based, district-based, and national-level, and these differ in terms of the range, or scope, of students involved 
(Takahashi 2006a; Fujii 2016). The Lesson Studies from which the final comments were analyzed in this study were school-based Lesson Studies. We collected data from three research lessons, as detailed in Table 1 . These were lessons in which Nakamura was koshi, where a lesson plan was available, and where there was a sense among participants that the students' thoughts in the lesson were particularly interesting and Nakamura's comments were typical of the kinds of comments he might make. Nakamura provided final comments to elementary schools in Yamanashi prefecture for 19 years. Consequently, he had the opportunity to build strong relationships with many schools and teachers, which created an environment likely to be supportive of the development of high-quality final comments. Hence, we chose Yamanashi prefecture for these research lessons.

For each research lesson, we obtained the lesson plans and audio and video recordings of the lessons and the Post-lesson Discussions, recorded with a digital voice recorder and a digital camera. Consent was obtained from the teacher and the students, and also from the participants in the Post-lesson Discussion. This research project was approved by the ethics committee of Tokyo Gakugei University.

The data were transcribed, and analysis was carried out from the transcripts and video. (Full transcripts of the lessons and final comments are available as online supplementary materials.) Data analysis was led by the research question, and we adopted a thematic approach (see Braun and Clarke 2006). Themes emerged from the data through identifying patterns as we watched the videos multiple times and carefully read the transcripts repeatedly. The transcripts from the Post-lesson Discussions were then coded according to the topics raised by Nakamura. Separate topics were defined according to pauses in Nakamura's speech immediately before them, or verbal cues from him that he was moving to a new subject. This allowed us to create a list of 'key points' made, in chronological order, from each research lesson (see Tables 2, 3, 4). We selected from each lesson one or two of these key points to expand on in more detail, so as to illustrate the kinds of comments made. Finally, we coded the 25 key points obtained across all three lessons in order to organize the points into themes, which we present as an overview of the issues discussed.

\section{The content of the final comments}

For each of the three research lessons, we now provide a table showing the key points made in the final comments, in the order that Nakamura made them. For each lesson, we focus on one or two of these comments in more detail in order to illuminate the kinds of remarks he made.

\section{Research Lesson 1}

This research lesson focused on decimals and aimed at enriching students' number sense by considering the number 2.8 in two ways: as a point on a number line and as a result of addition and subtraction calculations (e.g., $3-0.2,2+0.8$, etc.). In the introduction to the lesson, the teacher also asked students to think about the number 280 in different ways and then asked the students to consider the relationship between 2.8 and 280 .

In the Post-lesson Discussion of this research lesson, seven final comments were made by Nakamura (see Table 2), and we focus below on one of these that we feel is particularly useful in illustrating Nakamura's approach to making final comments. 


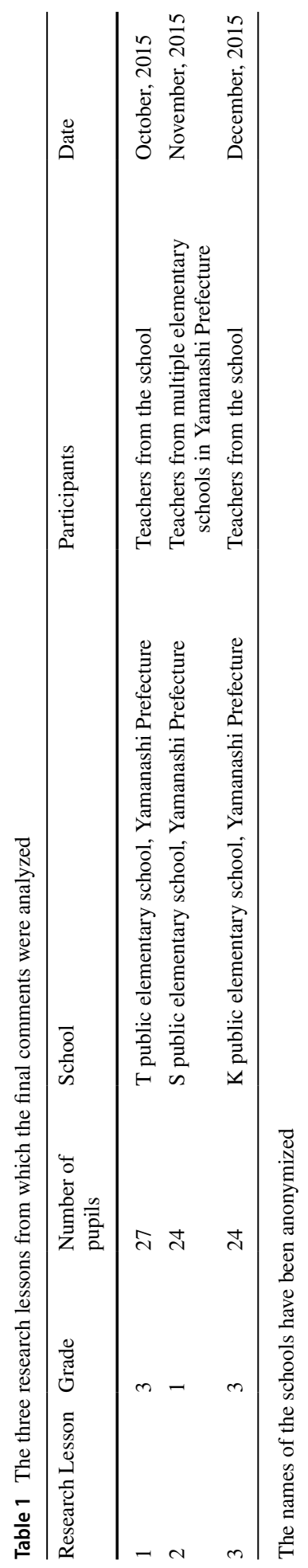




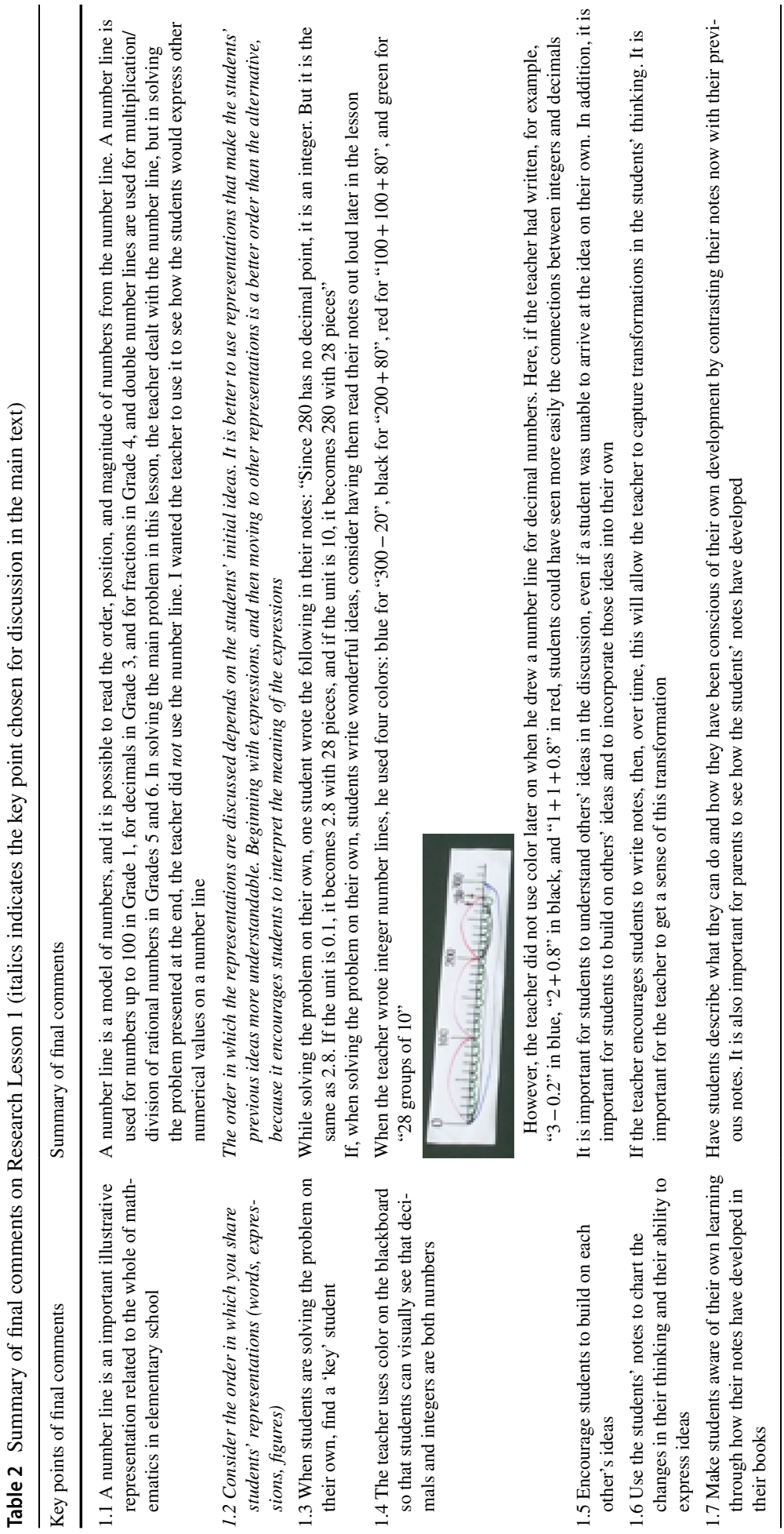




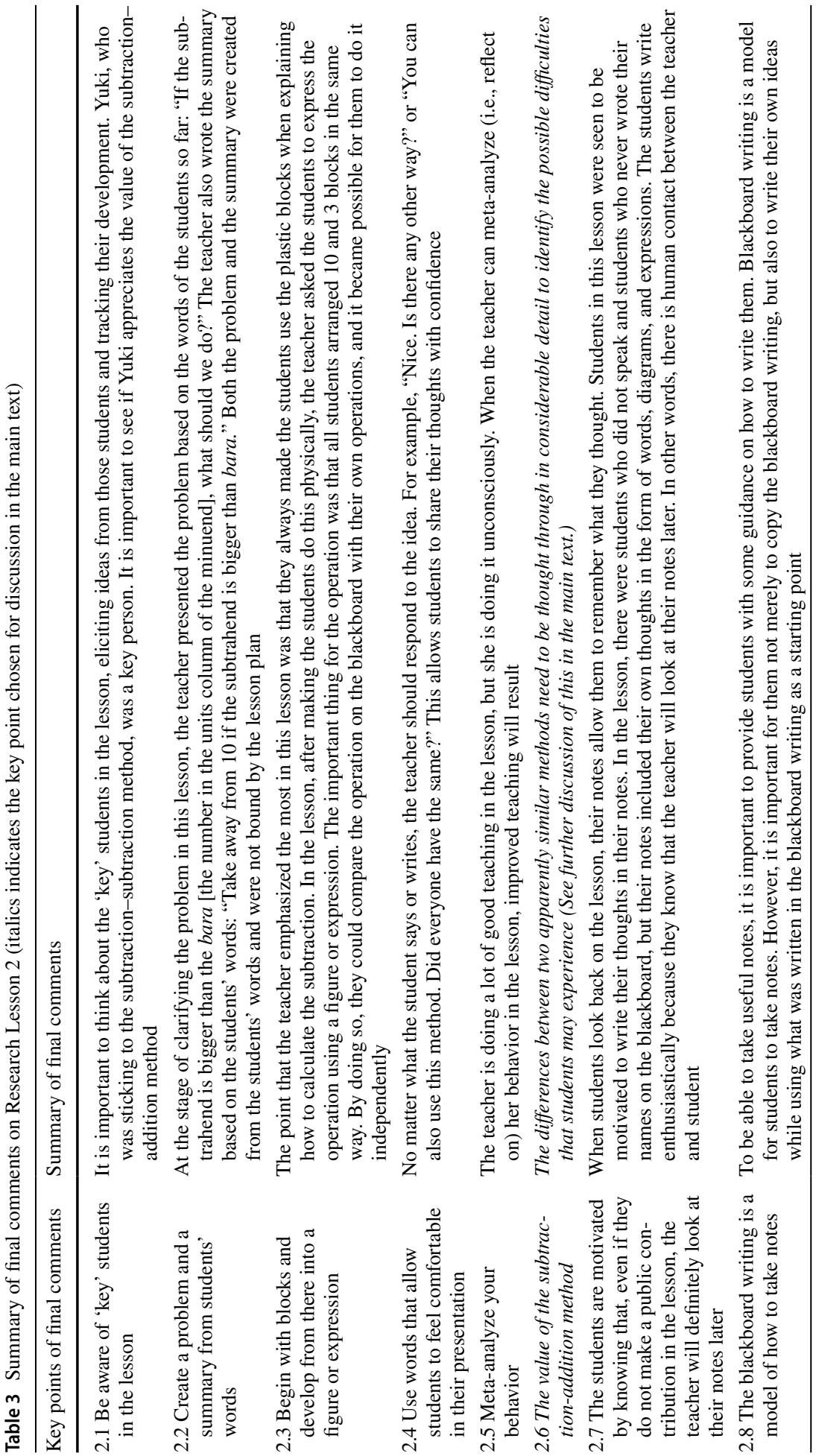




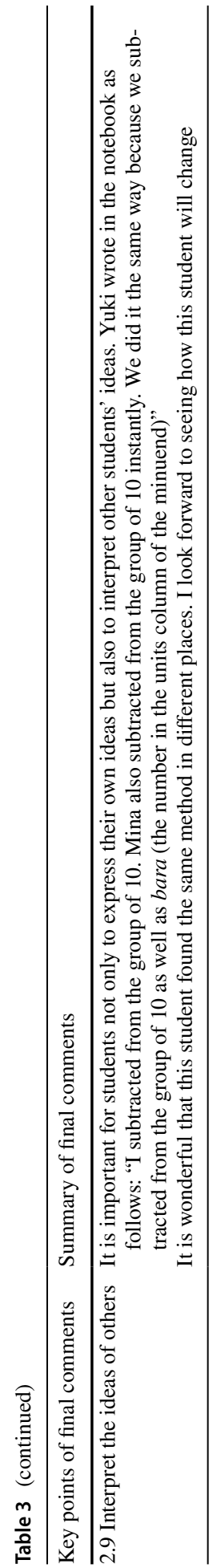

Springer 
Table 4 Summary of final comments on Research Lesson 3 (italics indicates the key point chosen for discussion in the main text)

Key points of final comments

3.1 Have students realize what they can now understand and to what extent

\subsection{Connect students' ideas with their previous knowledge}

3.3 When praising students, praise them concretely

3.4 Teach students not to erase what they have written

\subsection{Interpret students' ideas carefully}

3.6 Write students' words on the blackboard

3.7 Cultivate measurement sense

3.8 Be aware of 'key' students in the lesson

3.9 Record and analyze pictures of blackboard writing and students' notebooks
Summary of final comments

When studying mathematics, it is important for students to become aware of what they have understood and how much they can do

Make explicit connections between what students are learning now and any prior experiences that they have had that could contribute to the concepts

It is important to praise students' good points. Do not praise using general comments such as "You were good," but instead use concrete comments, such as "It was good that you used the word 'division'." Students will make use of the praised content for their subsequent learning

If students erase what they have written in their notebooks, the thought process disappears. It is important to teach students not to erase what they have written, even if they have made mistakes

When students misunderstand an idea, work hard at making sense of what they are saying and seeing how this relates to their prior experiences

By writing students' words on the blackboard, the teacher can make a summary of the lesson using the students' words. Students are aware that the summary is made with their words, and this helps their thinking

The aim of the lesson was to understand $1 / 3 \mathrm{~m}$, but, in this lesson, it was possible to cultivate a measurement sense for a length of $1 / 3 \mathrm{~m}$ by comparing 1 $\mathrm{m}$ and $1 / 3 \mathrm{~m}$. For that purpose, the teacher needed a way to compare the two quantities

Teachers should be conscious of 'key' students in the lesson, such as seeing whether a student who gives an incorrect answer to a question can later correctly answer that question. If the teacher can become aware of key students, the direction of the lesson will become clearer

The teacher keeps records of blackboard writing and "reflections of learning" regarding the students' notes in all lessons. Later, teachers objectively review the appropriateness of teaching and the growth of children from these records

\section{Thinking about the order in which students' representations are shared (Comment 1.2 in Table 2)}

In response to the prompt "Let's express 2.8 using words, expressions and number lines," the students offered " $2+0.8$," " $3-0.2$," and " $0.1 \times 28$ " (see Fig. 1). 


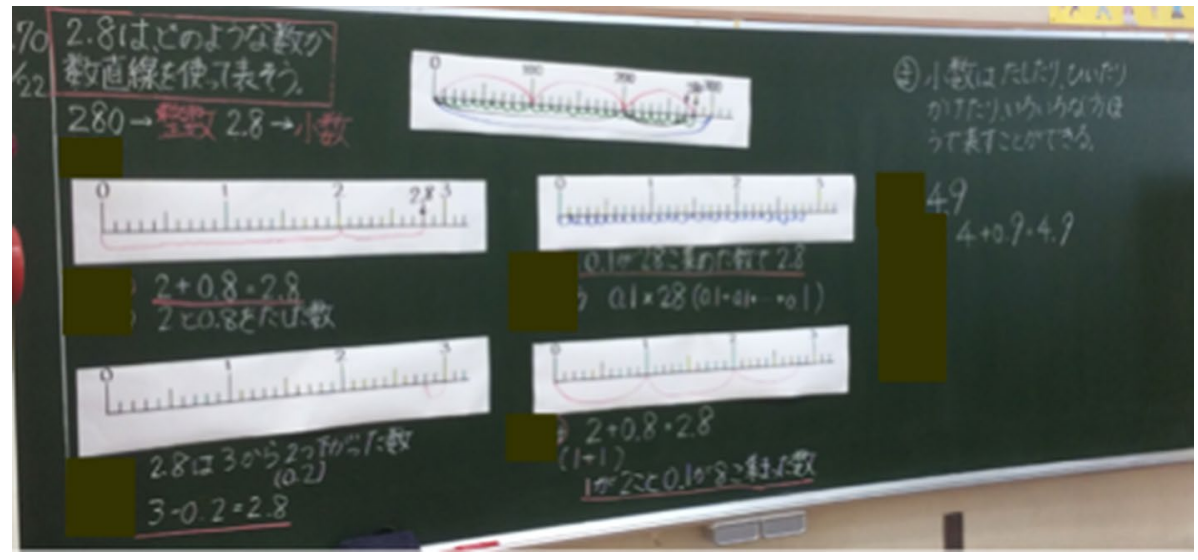

Fig. 1 Blackboard for Research Lesson 1

In the Post-lesson Discussion, Nakamura focused on the order in which the teacher shared the students' representations when comparing and discussing. First, the teacher called on Yumi (all student names here are pseudonyms), who thought of the number line when considering 2.8. The teacher then called on Yosuke, who thought of the expression " $2+0.8$." Finally, the teacher asked that the number line and expressions be expressed in words. Next, the teacher examined the idea of " $3-0.2$." First, the teacher called on Kaori, who explained the idea with words. Specifically, Kaori said that " 2.8 has dropped by 2 from 3" and "the number has dropped 0.2." The teacher then asked, "What expression could represent this?" and the student answered "3-0.2." The teacher then let the student draw a number line.

Nakamura said that it is important to clarify what the student was thinking when she said, "the number has dropped 0.2," and the number line was a useful tool to clarify this idea. Nakamura pointed out that because 0.2 in the words "the number has dropped 0.2" signifies two gradations on a number line, in order to make the student's idea clearer, the teacher could have taken up the idea of going down two gradations, rather than bringing in the idea of using an expression. In other words, if the teacher had deepened the meaning using Kaori's idea, Nakamura thought that the order of words, number lines, and expressions was good.

Nakamura pointed out that expressions, number lines, and words were not examined in this order, since the teacher did not begin with expressions in this lesson. For example, he referred to the following hypothetical lesson outline: The teacher takes up the
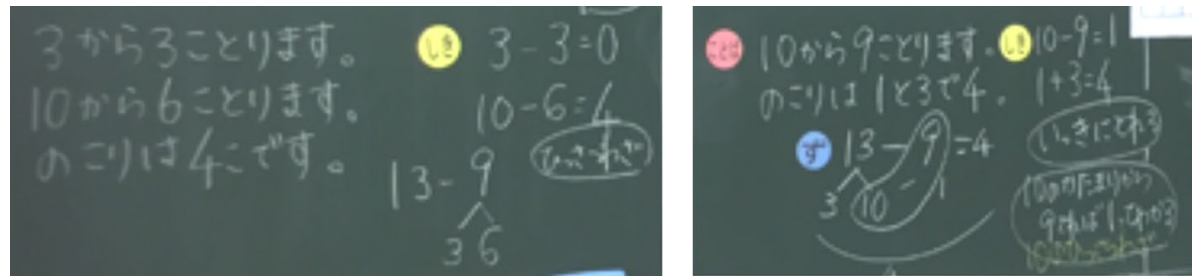

Fig. 2 The left side is the subtraction-subtraction method; the right side is the subtraction-addition method 
expression $1+1+0.8$ that a student provides and then has students represent the expression in words. Learning to start with expressions leads to an important activity of interpreting expressions in mathematics.

\section{Research Lesson 2}

This research lesson focused on a unit of subtraction involving regrouping and aimed at thinking about methods of calculation of 13-9. In this lesson, three main methods were presented and examined. Students explained these methods using words, figures, and expressions.

In the Post-lesson Discussion, nine final comments were provided (see Table 3), and we focus on one of these.

\section{The value of the subtraction-addition method (Comment 2.6 in Table 3)}

Two methods were examined to obtain the answer to $13-9$. The first was a method of partitioning 9 into 3 and 6 , subtracting 3 from 13, then subtracting 6 from 10 (subtraction-subtraction method). The other method was to partition 13 into 10 and 3, then to subtract 9 from 10, and add 3 to the 1 obtained (subtraction-addition method) (See Fig. 2 and Seino and Foster 2019).

Nakamura stated that the point of today's lesson was how students make sense of the value of the subtraction-addition method. He also pointed out that the two terms used by students in the lesson, "taking all at once" and "10," were key terms, while composing and decomposing of 10 (i.e., partitioning) was a fundamental idea. Furthermore, in the case of 13-9, when it was said to take 9 from 10, students knew where 9 was, but when it was said to take 6 from 10, the students did not know where the 6 was coming from. The number 6 was newly constructed. In the case of the subtraction-addition method, when calculating $14-9,1$ was added to 4 . When calculating $15-9,1$ was added to 5 . In other words, the answer was obtained by adding 1 to the number in the units column of the minuend. Nakamura pointed out that when this becomes apparent to students, it allows them to sense the value of the subtraction-addition method over the subtraction-subtraction method.

In the case of the subtraction-subtraction method, when students explained how to calculate $13-9$, they often did not explain it as obtaining an answer by subtracting and then subtracting further, but as follows: "I subtract 3 from 9, so I can get 6 . Next, I subtract 6 from 10, so I can get 4." In fact, however, they are considering 9 as 3 and 6 . If it is necessary to regroup in 2-digit and 3-digit calculations, the subtraction-subtraction method is difficult for students, because they cannot obtain the answer only by subtracting the number that is most apparent. So, firstly, students solved and mastered problems where the subtraction-addition method is easy to think about: for example, when the subtrahend is 8 or 9 . Secondly, students solved some problems where the minuend was close to the subtrahend: for example, $12-3$ or $17-8$. This is an easy way to think about the subtraction-subtraction method. However, Nakamura pointed out that by the end of Grade 1, addition and subtraction need to be proficient without using either the subtraction-addition method or the subtraction-subtraction method. 
Fig. 3 A tape with a line drawn at the position of a quarter

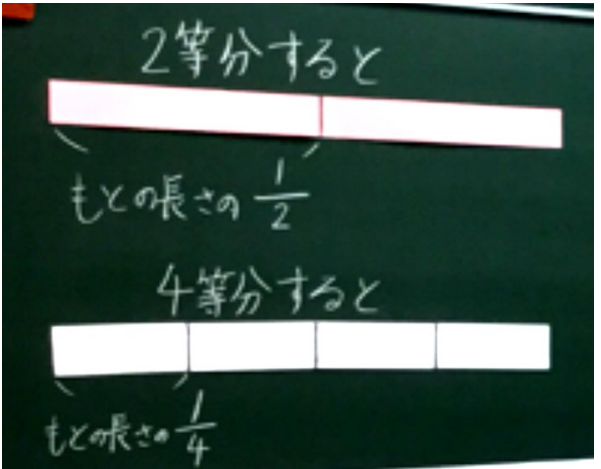

\section{Research Lesson 3}

This research lesson covered a unit on fractions with the aim of understanding what ' $1 / 3$ m' means. In Japan, fractions of a measured quantity, like this, are known as "quantitative fractions." In this lesson, the following contextual problem of finding treasure was used:

As sign on an island says: There is treasure buried $21 / 3 \mathrm{~m}$ from the tree. Use $1 \mathrm{~m}$ of tape and look for that treasure.

By solving this problem, it is intended that students make $1 / 3 \mathrm{~m}$ from a $1 \mathrm{~m}$ tape.

In the Post-lesson Discussion, nine final comments in total were made by Nakamura, as summarized in Table 4. We highlight two of these comments and describe how they related to incidents from the lesson.

\section{Connecting 'equally divided' to prior experiences with decimals (Comment 3.2 in Table 4)}

During the introduction to the lesson, the teacher reviewed the unit "dividing fractions" studied in Grade 2. At that time, the teacher had shown the students a tape with a line drawn at the center and had said that the tape was divided into two pieces of the same length by the center line. In the research lesson, a student used the terms "equally divided," and "bisection." In response to the student's remarks, the teacher asked, "What quantity is each of the two equal parts of an original length?" and the student answered " $1 / 2$." The teacher then showed the students a tape with a line drawn at the position of the quarter and asked the same question about 1/4 (Fig. 3).

In the Post-lesson Discussion, Nakamura pointed out that students had used the words "equally divided" and "bisection" in the introduction to the lesson. Then, he asked the

Fig. 4 Pair A's idea

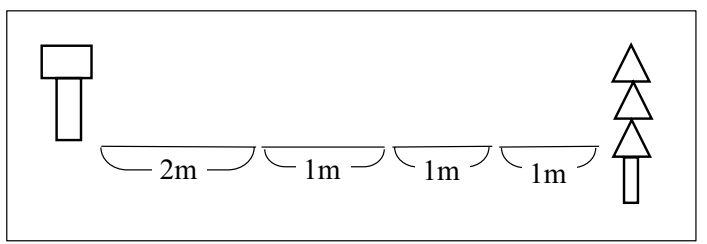


Fig. 5 Pair D's idea

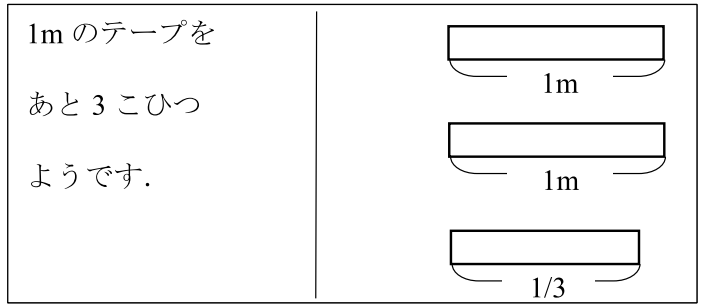

participating teachers: When did the students learn the phrase "equally divided?" This question provided teachers with an opportunity to think deeply about the previous knowledge that students had acquired. Nakamura also pointed out decimal numbers and division as learning units in which the phrase "equally divided" is used. When students learn partitive division, they use the term "equally divided." In the case of decimal numbers, when students learn that "When $1 \mathrm{~L}$ is divided into 10 equal parts, each part is written as $0.1 \mathrm{~L}$," students use the phrase "equally divided." Therefore, Nakamura advised as follows: When students say the phrase "equally divided," the teacher should ask "Where did you learn the phrase 'equally divided'?" and elicit previous knowledge from students. He explained that such interaction leads students to become aware that fractions are related to division and decimal numbers. Nakamura also took up the remark of one student that " $1 / 3$ means dividing, so it is similar to division," and explained that this student had begun to connect fractions and division. This idea will later be connected with the fraction $2 \div 3=2 / 3$ that is learned in Grade 5 .

\section{Interpreting students' ideas carefully (Comment 3.5 in Table 4)}

After students worked on the 'treasure' problem (see above), four pairs of students shared their ideas. Pair A's idea was written on a small blackboard: "I know $2 \mathrm{~m}$. Because $1 / 3 \mathrm{~m}$ is the length of three $1 \mathrm{~m}$ tapes, I arrange three $1 \mathrm{~m}$ tapes next to $2 \mathrm{~m}$ " (Fig. 4). This was a misunderstanding. Pairs B and C then shared their ideas: "I fold the $1 \mathrm{~m}$ tape into three equal pieces. The crease becomes 1/3 m." Finally, pair D shared their idea: "I need 3 more $1 \mathrm{~m}$ lengths of tape" (Fig. 5). This was also a misunderstanding.

The teacher then said that pairs A and D had had similar ideas of a $1 \mathrm{~m}$ tape as adding three, while pairs $\mathrm{B}$ and $\mathrm{C}$ had had similar ideas of equally dividing a $1 \mathrm{~m}$ tape into three parts. The teacher then divided the ideas into two pairs (A and D, B and C) on the blackboard.

In the Post-lesson Discussion, Nakamura focused on the episode where the ideas of pairs A, B, C, and D had been divided into two groups, and he discussed why he thought that the students had viewed a $1 \mathrm{~m}$ tape as adding three. Like the idea of pair D, from the students' perspective, $2 \mathrm{~m}$ and $1 / 3 \mathrm{~m}$ can be divided into 3 pieces by $1 \mathrm{~m}$ (see Fig. 5), comprising two $1 \mathrm{~m}$ tapes and one-third. When examining them side by side, each seems to be divided into three. Considering it in this way, $1 / 3$ is the same as $1 \mathrm{~m}$. Therefore, when expressing $2 \mathrm{~m}$ and 1/3, pair D assumed that three $1 \mathrm{~m}$ tapes were needed. After providing the above interpretation, Nakamura noted that pairs A and D demonstrated difficulties in terms of what is considered to be the unit, ' 1 ', and what is considered to be the base quantity, when equally divided.

While understanding students' ideas is difficult, it is even more difficult to understand why students come up with such ideas. Nakamura pointed out the importance of interpreting students' ideas politely and properly. 
Table 5 Categorization of final comments

\begin{tabular}{lll}
\hline Theme & Category & Related comments \\
\hline Mathematical didactics & $\begin{array}{l}\text { 1. Considering the didactical value of mathemati- } \\
\text { cal content }\end{array}$ & $2.6,3.2,3.7$ \\
& $\begin{array}{l}\text { 2. Use of representations } \\
\text { 3. Fostering positive attitudes to learning }\end{array}$ & $1.1,1.2,2.3$ \\
Focus on students & $\begin{array}{l}\text { 4. Incorporating students' ideas into whole-class } \\
\text { discussions }\end{array}$ & $1.5,2.4,2.9,3.1,3.2,3.3$ \\
& $\begin{array}{l}\text { 5. Giving attention to what students write down } \\
\text { 6riting }\end{array}$ & $1.6,1.7,2.2,2.9,3.5,3.8$ \\
& Work & $1.4,2.8,3.6,3.9$ \\
The teacher & 7. Teacher growth through reflection & $2.5,3.9$ \\
\hline
\end{tabular}

\section{Topics discussed by knowledgeable other}

In this section, we bring together all 25 of the final comments captured in these three research lessons described above, 7 from the first lesson, and 9 from each of the second and third lessons. We analyzed the content of these comments and organized them into seven categories, which we describe below. We further organized these categories into four overarching themes: The first two categories could be summarized as an analysis of mathematical didactics (see Andrews 2007), the third and fourth categories as focusing on students, the fifth and sixth as focusing on writing, and the seventh as relating to teacher growth (see Table 5). We now consider these seven categories in turn and, where possible, relate the points made to the wider research literature.

\section{Considering the didactical value of mathematical content}

A vital aspect of lesson planning is to consider the didactical details (Andrews 2007) of different mathematical content and methods (e.g., see Seino and Foster 2019). This focus was apparent in many of Nakamura's comments, including 2.6, 3.2, and 3.7, where he delved into considerable detail about aspects of particular methods and examples used in the lessons. He definitely believed that 'the devil is in the detail,' and did not shy away from engaging participants in in-depth discussions about the mathematics and the pros and cons of alternative methods or choices of examples. At times, this included helping the participants to appreciate features of the design of the textbook examples and explanations that they may not have been previously aware of.

In relation to this, Nakamura repeatedly stressed the importance of making links to students' prior knowledge (e.g., comment 3.2 discussed above). This echoes Ausubel's (1968, p. iv) often-quoted remark: "If I had to reduce all of educational psychology to just one principle, I would say this: The most important single factor influencing learning is what the learner already knows; ascertain this and teach him[her] accordingly". It is vital for teachers to consider what prior experiences their students may bring to the lesson and for the teacher to be explicitly linking what is being learned with things that they have 'met before' (McGowen and Tall 2010). 


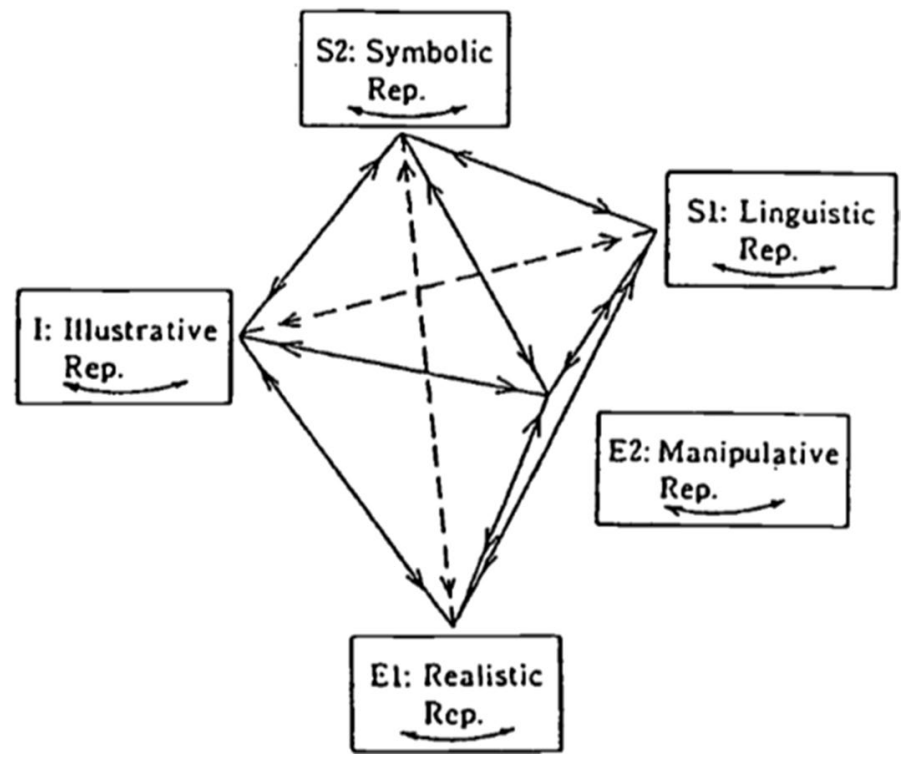

Fig. 6 (External) representational system in mathematics education. Taken from Nakahara and Koyama (1998, p. 92)

\section{Use of representations}

This category concerns the analysis of the educational value of mathematical representations of the various kinds shown in Fig. 6 (Nakahara and Koyama 1998). Nakamura explained how to use different mathematical representations effectively, and their significance in the lessons (e.g., see comments 1.1, 1.2 and 2.3). He particularly stressed the importance of representations being presented in an optimal order that allowed students to build up their ideas in a gradual fashion (see, for example, the discussion above of comment 1.2).

Nakamura's final comments contain many remarks on mathematical expressions, as reflected in his words from a book he wrote:

Thinking and expressing are inseparably related. Thinking is manifested by writing. You can also review your thinking from what you have written. In math lessons, we aim not only to acquire fundamental and basic knowledge and skills but also to develop thinking and expressing skills by using fundamental and basic knowledge and skills. It is easy to see if students have acquired knowledge and skills, but it is difficult to grasp their ability to think and express. Therefore, I will focus on mathematical expressions and attempt to grasp mathematical thinking from the expressions. (Translated from the original Japanese by the first author) (Nakamura 2010, p. 1)

Nakamura's thinking on this is supported by much research on the value of representations in the learning of mathematics (e.g., Nunes et al. 2009; see also Hodgen et al. 2018). 


\section{Fostering positive attitudes to learning}

Nakamura considered it important to make students aware of what they have become able to understand, as well as what they do not yet understand:

In math lessons, having children accurately grasp the situation of their own learning will foster the ability to think, and broaden their way of viewing and thinking... The role of the teacher is to nurture children to continue learning while self-assessing, and to give children the responsibility for learning. (Translated from the original Japanese by the first author) (Nakamura 2011a, pp. 122-123)

Nakamura considered the role of the teacher to be to help students acquire the attitude of continuing learning while self-assessing. He made several final comments about helping students to realize what they have understood and how they have developed (e.g., 3.1, $3.2,3.3$ ). This kind of self-awareness is an aspect of metacognition, which appears to be important for the learning of mathematics (Donovan and Bransford 2005).

He also commented that it is important to praise students' ideas and create an atmosphere in which students can speak freely and listen to one another (e.g., comments 1.5, 2.4, 2.9 and 3.3). Nakamura stated that it is important for students not only to express their own ideas but also to interpret other students' thoughts (e.g., see comment 1.5). Nakamura stated that if students have a positive view of learning, the atmosphere of the class changes, and an empathic class culture is created in which each other's opinions are respected and accepted. Research suggests that positive attitudes to mathematics can foster students' attainment (Ma and Kishor 1997).

\section{Incorporating students' ideas into whole-class discussions}

Nakamura stated that it is important to listen carefully to students' ideas and build them into the lesson (e.g., see comment 2.2 and comment 3.5). He also noted that it is important that the summary be expressed using the language of the students in the lesson (comment 2.2). Both teacher and students should listen carefully to students' ideas. Even if students cannot solve the problem on their own, they may develop by listening to other students' ideas at the time of discussion and use those ideas to solve further problems (see comment 2.9). The role of the teacher is to provide an opportunity to use others' ideas.

Nakamura noted repeatedly that it is important for teachers to be aware of particular, 'key' students in the lesson, whose insights may be especially beneficial to the whole class, and to draw these students into the whole-class discussion (see comments 1.3, 2.1 and 3.8). The teacher may have an idea in advance about who these students may be, or it may become apparent during the lesson. Structuring a productive plenary is an important skill for the mathematics teacher to develop (see Stein et al. 2008; Takahashi 2008).

\section{Giving attention to what students write down}

This category concerns the writing in students' notebooks. Nakamura placed great importance on writing, for the following reasons:

One is for the children to review their ideas and make them better. The other is to activate the interaction between children. Writing is closely related to thinking. 
When you think about a problem, you analyze the structure of the problem by writing algebraic expressions, drawing additional lines on geometrical figures, and using words and figures. By writing, even if your thoughts are vague, they become apparent and can be reviewed. That is done to confirm the validity of what you are thinking now. In addition, expressing your thoughts in expressions, diagrams, and words will enable you to convey your thoughts to others. (Translated from the original Japanese by the first author) (Nakamura 2002, p. 5)

Clearly, Nakamura considered writing an important activity, because it leads to reflection on thinking and interaction between students. Therefore, he made many comments in the Post-lesson Discussions on the teaching of notetaking (e.g., see comments 1.6, 1.7, 2.7, 3.4 and 3.9). Nakamura intended notes to be used to evaluate thinking. In particular, he stressed evaluating thinking ability from the "reflection of learning" in students' notes. Stressing the importance of students' notes is highly characteristic of Japanese teaching.

\section{Giving attention to the content of the board-work}

This category concerns the content of the blackboard writing, which Japan has traditionally emphasized (bansho) (see Takahashi 2006b; Takahashi and Yoshida 2004). Nakamura also emphasized the importance of this:

Children can concretely know the process of thinking and various expressions by indicating the name of the child so that it can be understood who presented what idea, writing exactly what the child said on the blackboard, and writing not only the expressions, but also the figures and words on the blackboard. Blackboard writing is an important activity that contributes to the flow of lessons. (Translated from the original Japanese by the first author) (Nakamura 2011b, p. 9)

Nakamura emphasized the need to write students' ideas accurately on the board and to include their names beside them (e.g., see comments 1.4, 3.6 and 3.9). He also stated that blackboard writing plays a role in deepening understanding of mathematical knowledge and becoming a model for notes (comment 2.8). The emphasis on the content of the boardwork in Japanese classrooms contrasts starkly with perspectives in other countries (see Foster and Baldry 2020; Baldry et al. in preparation).

\section{Teacher growth through reflection}

\section{According to Nakamura:}

In order to reflect on our practice, we would like to collect materials to understand our own lessons objectively. Concretely, it is to copy the blackboard writing of each lesson to a notebook and to take a photo of it with a digital camera... we also want to see the children's notes continuously. This is not only to evaluate the children's understanding of learning but also to evaluate the teacher's own lesson.... Teachers who have many resources that can reflect on their practice develop. (Translated from the original Japanese by the first author) (Nakamura 2008, p. 9) 
Recording and analyzing the blackboard writing in lessons supports teachers' growth. In addition, analyzing students' notes, particularly their "reflection of learning," helps teachers not only to evaluate the students' understanding but also to reflect on their own lessons (see comments 2.5, 3.9). Much research has focused on the ways in which teachers can develop through becoming 'reflective practitioners' (Schön 1986; see also Mason 2002).

\section{Conclusion}

Attempts in countries outside Japan to adopt and adapt aspects of lesson study for use in their own schools, especially in mathematics, have sometimes found the role of the koshi particularly difficult to imitate (e.g., Baldry and Foster 2019), whereas, in Japan, lesson study is so familiar it can be hard to notice what is important (Fujii 2014). In this paper, we have sought to examine this crucial aspect of successful lesson study in Japan in order to identify practices that contribute to the value of the process and enable them to be analyzed.

We have analyzed the final comments provided during Post-lesson Discussions across three mathematics research lessons by a very highly regarded koshi, Professor Takashi Nakamura, a university mathematics educator with extensive elementary school teaching experience and an outstanding public reputation in Japan. The comments of a koshi play an extremely important role in helping mathematics teachers to develop their practice. Although the importance of the knowledgeable other has been recognized in previous research (e.g., Fernandez et al. 2001; Takahashi and Yoshida 2004; Watanabe and WangIverson 2005; Takahashi 2014), there was a lack of research on what kinds of final comments might be most helpful.

We organized Nakamura's comments across three research lessons into seven categories (see Table 5 above), and we believe this structure to be useful in understanding the kinds of final comments that may be productive when conducting lesson study. Clearly, this is just a starting point, based on the comments of just one koshi, albeit an outstanding one, and it would be important to repeat this process looking at a wider variety of koshis, across a wider range of research lessons covering different ages of students and different mathematical topics. We hope to address this in our future research. However, we suggest that these categories might support less-experienced koshis in considering the kinds of comments that they might plan to make following a research lesson. They may also be useful for teachers to consider at the early stages of lesson design or Kyouzai kenkyuu (Takahashi and McDougal 2016).

Acknowledgements This work was supported by the Japan Society for the Promotion of Science KAKENHI (Grant Nos. JP16K21022, JP17K00956 and 24300268) and by the Economic and Social Research Council (Grant No. ES/S014292/1).

Open Access This article is licensed under a Creative Commons Attribution 4.0 International License, which permits use, sharing, adaptation, distribution and reproduction in any medium or format, as long as you give appropriate credit to the original author(s) and the source, provide a link to the Creative Commons licence, and indicate if changes were made. The images or other third party material in this article are included in the article's Creative Commons licence, unless indicated otherwise in a credit line to the material. If material is not included in the article's Creative Commons licence and your intended use is not permitted by statutory regulation or exceeds the permitted use, you will need to obtain permission directly from the copyright holder. To view a copy of this licence, visit http://creativecommons.org/licenses/by/4.0/. 


\section{References}

Andrews, P. (2007). Conditions for learning: A footnote on pedagogy and didactics. Mathematics Teaching, 204, 22.

Ausubel, D. (1968). Educational psychology. New York: Holt, Rinehart \& Winston.

Baldry, F., \& Foster, C. (2019). Lesson study in mathematics initial teacher education in England. In R. Huang, A. Takahashi, \& P. da Ponte (Eds.), Theory and practice of lesson study in mathematics: An international perspective (pp. 577-594). Cham: Springer.

Baldry, F., Mann, J., Horsman, R., Koiwa, D., \& Foster, C. (in preparation). How carefully-planned boardwork can support the productivediscussion of multiple student responses to a problem-solving task.

Ball, D. L., Thames, M. H., \& Phelps, G. (2005). Content knowledge for teaching: What makes it special? Journal of Teacher Education, 59(5), 389-407.

Braun, V., \& Clarke, V. (2006). Using thematic analysis in psychology. Qualitative Research in Psychology, 3(2), 77-101.

Donovan, M. S., \& Bransford, J. D. (2005). How students learn: Mathematics in the classroom. Washington, DC: The National Academies Press.

Fernandez, C., \& Yoshida, M. (2012). Lesson study: A Japanese approach to improving mathematics teaching and learning. New York: Routledge.

Fernandez, C., Yoshida, M., Chokshi, S., \& Cannon, J. (2001). An overview of lesson study. Lesson study research group. Retrieved April 8, 2019 from https://valerievacchio.files.wordpress.com/2011/11/edu77 01-intro_to_lesson_study.pdf.

Foster, C., \& Baldry, F. (2020). Blink, and it's gone! Mathematics Teaching, 270, 12-13.

Fujii, T. (2014). Implementing Japanese lesson study in foreign countries: Misconceptions revealed. Mathematics Teacher Education and Development, 16(1), 65-83.

Fujii, T. (2016). Designing and adapting tasks in lesson planning: A critical process of lesson study. ZDM: The International Journal on Mathematics Education, 48(4), 411-423.

Groves, S., \& Doig, B. (2016). The role of the knowledgeable other in post-lesson discussions in lesson study. In Proceedings of the 40th conference of the international group for the psychology of mathematics education (pp. 315-322). International Group for the Psychology of Mathematics Education.

Groves, S., Doig, B., Vale, C., \& Widjaja, W. (2016). Critical factors in the adaptation and implementation of Japanese lesson study in the Australian context. ZDM: The International Journal on Mathematics Education, 48(4), 501-512.

Hodgen, J., Foster, C., Marks, R., \& Brown, M. (2018). Evidence for review of mathematics teaching: Improving mathematics in key stages two and three. London: Education Endowment Foundation. Retrieved from https://educationendowmentfoundation.org.uk/public/files/Publications/Maths/EEF_Maths_Evidence_ Review.pdf.

Lewis, C. (2002). Lesson study: A handbook of teacher-led instructional change. Philadelphia: Research for Better Schools Inc.

Ma, X., \& Kishor, N. (1997). Assessing the relationship between attitude toward mathematics and achievement in mathematics: A meta-analysis. Journal for Research in Mathematics Education, 28(1), 26-47.

Mason, J. (2002). Researching your own practice: The discipline of noticing. London: Routledge.

McGowen, M. A., \& Tall, D. O. (2010). Metaphor or Met-Before? The effects of previous experience on the practice and theory of learning mathematics. The Journal of Mathematical Behavior, 29(3), 169-179.

Nakahara, T., \& Koyama, M. (1998). Study of the constructive approach in mathematics education. In Mathematics teaching from a constructivist point of view. Proceedings of topic group 6 at the international congress on mathematical education (8th, Seville, Spain). Faculty of education report no. 3 (pp. 85-103).

Nakamura, T. (2002). "Kakukatsudou” wo tooshite suugakuteki na kangaekata wo sodateru sansuujyugyou [Mathematics lessons to develop mathematical thinking through 'activities of writing']. Tokyo: Toyokan syuppansya.

Nakamura, T. (2008). Hikakukentou no ba niokeru jyugyou no doramasei [Lesson as drama in the phase of discussing] (Vol. 1274, pp. 14-17). Tokyo: Kyouikukenkyu.

Nakamura, T. (2010). Korede sodatsu. Suugakuteki na hyougenryoku [How to foster the ability of mathematical representation]. Tokyo: Toyokan syuppansya.

Nakamura, T. (2011a). Suugakuteki na shikouryoku hyougenryoku wo nobasu sansuujyugyou [Mathematics lessons to develop the ability of mathematical thinking and expressions]. Tokyo: Meijitosho.

Nakamura, T. (2011b). Suugakuteki na shikouryoku hyougenryoku no ikusei to kyoukasyo no katsuyou [Developing the ability of mathematical thinking and expressions, and making use of textbook] (pp. 7-9). Tokyo: Tanoshii sansuu no jyugyou.

Nunes, T., Bryant, P., \& Watson, A. (2009). Key understandings in mathematics learning. London: Nuffield Foundation. 
Rowland, T. (2008). Researching teachers' mathematical disciplinary knowledge. In P. Sullivan \& T. Wood (Eds.), International handbook of mathematics teacher education: Vol. 1. Knowledge and beliefs in mathematics teaching and teaching development. Rotterdam: Sense Publisher.

Schön, D. (1986). Educating the reflective practitioner. San Francisco: Jossey Bass.

Seino, T., \& Foster, C. (2019). Why the details matter: Learning from Japanese Kyouzai kenkyuu. Mathematics in School, 48(5), 2-8.

Shulman, L. S. (1986). Those who understand: Knowledge growth in teaching. Educational Researcher, 15, 4-14.

Stein, M. K., Engle, R. A., Smith, M. S., \& Hughes, E. K. (2008). Orchestrating productive mathematical discussions: Five practices for helping teachers move beyond show and tell. Mathematical Thinking and Learning, 10(4), 313-340.

Stigler, J. W., \& Hiebert, J. (1999). The teaching gap: Best ideas from the world's teachers for improving education in the classroom. New York: The Free Press.

Takahashi, A. (2006a). Types of elementary mathematics lesson study in Japan: Analysis of features and characteristics (in Japanese). Journal of Japan Society of Mathematical Education, Mathematics Education, $88(8), 2-14$.

Takahashi, A. (2006b). Characteristics of Japanese mathematics lessons. Tsukuba Journal of Educational Study in Mathematics, 25(1), 37-44.

Takahashi, A. (2008). Beyond show and tell: Neriage for teaching through problem-solving-Ideas from Japanese problem-solving approaches for teaching mathematics. In 11th international congress on mathematics education in Mexico (Section TSG 19: Research and development in problem solving in mathematics education), Monterrey, Mexico.

Takahashi, A. (2014). The role of the knowledgeable other in lesson study: Examining the final comments of experienced lesson study practitioners. Mathematics Teacher Education and Development, 16(1), 4-21.

Takahashi, A., \& McDougal, T. (2016). Collaborative lesson research: Maximizing the impact of lesson study. ZDM: The International Journal on Mathematics Education, 48, 513-526. https://doi.org/10.1007/s1185 8-015-0752-X.

Takahashi, A., \& Yoshida, M. (2004). Ideas for establishing lesson-study communities. Teaching Children Mathematics, 10(9), 436-443.

Wada, Y. (1953). Shidouhou to sono kenkyuu [A study of the method of teaching]. Journal of the Mathematical Educational Society of Japan, 2(2), 33-36.

Watanabe, T. (2002). The role of outside experts in lesson study. In C. Lewis (Ed.), Lesson study: A handbook of teacher-led instructional improvement (p. 32). Philadelphia, PA: Research for Better Schools.

Watanabe, T., \& Wang-Iverson, P. (2005). The role of knowledgeable others. In P. Wang-Iverson \& M. Yoshida (Eds.), Building our understanding of lesson study (pp. 85-91). Philadelphia, PA: Research for Better Schools.

Yoshida, M. (1999). Lesson study: A case study of a Japanese approach to improving instruction through school-based teacher development (Unpublished doctoral dissertation). University of Chicago, Chicago.

Publisher's Note Springer Nature remains neutral with regard to jurisdictional claims in published maps and institutional affiliations. 